\title{
Child Neglect
}

\author{
Sudiyanto \\ Working Group on Child Development and Social Pediatrics, \\ Indonesian Society of Pediatricians, Indonesia)
}

\begin{abstract}
Arstract Child neglect refers to failure to provide children's fundamental needs. In contrast to child abuse, which implies active negative conduct; child neglect means something passive. Child neglect may take a variety of forms including medical, physical, safety, sexual, educational, and emotional neglects. The neglects may manifest themselves as conditions reflecting the improper provision of child's needs. It should always borne in mind that child neglect is almost invariably resulted from complex process which has been influenced by family history, individual characteristics of the parents and children, social and environmental circumstances, and medical problems. Its management, therefore, should be thoroughly administered, and should involve many aspects and all parties in a team effort. The prevention of child neglect should include formal and informal education of the rights of the child. [Paediatr Indones 1995;35:113-117]
\end{abstract}

\section{Defining Child Neglect}

Parents, guardians, or custodians have responsibilities to their children. They must provide food, clothing, shelter, health care, education, a safe environment, and emotional support. Child neglect refers to inadequate provision of or failure to provide adequately these fundamental needs, which is something

Presented at the 3rd Asian Conference on Child Abuse and Neglect 8-11 January 1993, Kuala Lumpur, Malaysia. Author's address: Sudiyanlo, MD, Department of Child Heath. Medical School, University of Indonesia, Jalan Salemba 6, Jakarta 10430, Indonesia. Tel 62-62-3907742, Fax. 62-21-3907743 passive process and there is no intent to harm the child, resulting from of lack of motivation, poor judgment, or poor understanding of the child's needs and developmental stages. Child neglect is in contrast with child abuse which is something active or an act of aggression, and the result of active maltreatment by parents, guardians, or custodians (PGC). ${ }^{1,2}$

\section{Forms of Neglect}

Child neglect is manifested in many ways and takes several forms, i.e., physical, sexual, safety, educational, and 
emotional neglect. Other forms include abandoned, illegally plated for adoption, loss of parental care, such as filthy or unsanitary home, permitting a child become dependent, neglected, abused or delinquent, or failure to impose appropriate discipline. ${ }^{1,2}$

Medical neglect may be defined as the failure of the PGC (parents, guardians, custodians) to provide the medical needs of the child. Including here are the failure to seek timely and appropriate medical care for illness and injuries, and lack of compliance with prescribed treatment resulting in impairment of the child's health and places the child at risk of serious consequences.

Physical neglect may be defined as the failure of the PGC to provide the child's most basic and immediate needs, namey food with age-appropriate diet, and shelter. Safety neglect is defined as the failure of the PGC to provide a safe environment with proper supervision, such as safe medicines, free of poisons, availability of firearms in the home, car re straints, safe age-appropriate toys, and continuous and appropriate adult supervision.

Educational neglect may be defined as PGC's inability or unwillingness to ensure a child's school attendance, including permitting a chronic truancy, for example, allowing a child to miss school for trivial reasons, keeping a child at home for inappropriate purposes such as to work or to baby-sit, failing to obtain recommended special education services.

Emotional neglect is defined as a lack of nurturing and psychological support for the child by the PGC. This differs from active behavior in emotional abuse, where a child's psyche is attacked by verbal abuse and instillation of fears. Psychological abuse process has five levis, namely, (1) rejecting-not acknowledging a child's worth and importance, (2) isolating-separating a child from friends to prevent the child from learning through social relationships, (3) terrorizing- using verbal abuse to frighten the child and create fears that are not well founded, (4) ignoring-depriving the child of stimulation, and (5) corrupting-forcing a child to engage in antisocial behavior. Of those, ignoring is the most passive and is, in essence, emotional neglect.

Sexual child neglect may be defined as the failure of the PGC to provide direct protection or education that make the child is more able to protect her/himself or the PGC let the child be exposed carelessly to pornographic materials or adult sexual activity, and put the child at risk of sexual abuse. ${ }^{1}$

\section{Evidence of Neglect}

Evidence of child neglect can be direct or indirect according to the forms of neglect. Evidence of medical neglect can be identified by the possible consequences which may take the forms such as repeated avoidable ungent visits for health care, delayed diagnosis, no response to treatment, complications, or school ab sences. Medical neglect may also take forms as malformed infant, small for gestational age baby of the newborn in poor nutrition, missed appointments, and substance abuse of the mother, hypoxia, brain damage, and death of newborn delivered at home when ill-advised or against medical advice and refusal to consent to procedure for infant. Congestive heart failure in heart diseace, diabetic ketoacidosis in diabetes mellitus, recurrent seizures in epilepsy, wheezing episodes, avoidable emergency room visits or hospital admissions in asthma, poor growth, mental retardation in hypothyroidism may also manifestations of child neglect.

Physical neglect may have the evidence of inadequate bathed, inadequate clothed, pale, undernourished, dirty child with smells of stool of urine, scabies, and dermatitis. Others including substandard home conditions with improper heating and ventilation, toilets and sinks which do not function well, improper garbage accumulation and disposal, presence of rodents and insects, inadequate cooking facilities and inadequate food.

Repeated episodes of preventable injuries may present the evidence of safety neglect. Children having missed more than 25 percent of school days may pre sent the evidence of educational neglect.

Evidence of emotional neglect may be identified in children who are not interested in feeding, rarely smile, do not explore their environment, have motor and language delay, or turn their attention inward. Children who are depressed, extremely aggressive, fail to thrive, have find it difficult to love others and to interact with other children and adults in society, withdrawal, poor school performance, attachment disorder, attention seeking behavior, may also reflect emotional neglect.

Evidence of sexual neglect can be traced to the behavior patterns of the child related to pornographic materials or adult sexual activity, and that there are genital or anal injuries once he/she is sexually abused.

\section{Factors Predisposing Child Neglect}

Whenever child neglect occurs it must be seen as the result of a complex process which has been influenced by the family's history, individual characteristics in the parents and children, social and environmental circumstances, medical problems, and chance crisis. Children born to single mothers, or to parents who are very young, poor with inadequate finances, poor education, unprepared for the responsibilities of parenthood, isolated with limited family and community support, are at inreased risk of being neglected.

\section{Interventions}

The aims of interventions and treatment may be defined as to keep the child safe, to promote the child's development, to improve family's relationships and functioning. Strategies to pursue the aims of interventions and treatment should be executed by adoption of existing services, mobilizing community resources, and specific projects. Utilization of existing services needs change of attitude, change in pattern of working, extra training, extra staff support, and improved communications. In mobilizing community resources, sometimes special resources, including family centers, resi- 
dential provision, lay programs, and substitute care are needed. The substitute care may be shared, part of rehabilitation plan, or permanent, in day care, residen tial home or institution, foster family, adoptive family. The Malaysian experience of the management of child abuse and neglect pertaining to mandatory reporting, the child as a witness, punish ment or rehabilitation, and the rights of the child may be considered, adopted and tailored to the available resources.

\section{Intervention and Treatment Monitoring}

Thorough, continuous, comprehensive monitoring of the intervention and treatment of child neglect is a must considering the fact that each case of child neglect needs careful individual assessment. The therapeutic response must be tailored to meet the needs of the individual child and the individual family for the success of the intervention and treatment. Standardized forms listing all essential information required in reporting and documenting intervention, treatment, and follow-up care of child neglect should be developed to assure acceptance and utility by all parties concerned such as physicians, children's services workers, psychologists, psychiatrists, nurses, attorneys, judges.

\section{Conclusions}

The recognition and management of child neglect are important issues in pediatrics and child welfare. Besides the immediate problems related directly to the risks of inadequate physical, medical, emotional support, education, and safety precautions, that can be remedied by altering the child's environment, there are other longer-reaching consequences of child neglect. Neglect victims may manifest aggressive behavior and difficulties relating to peers that persist long after correction of the home situation is made. There is also evidence suggesting that these children may develop delinquent behavior and may become neglectful and abusive parents themselves.

For these reasons, it is important and strongly recommended to develop methods to prevent child neglect from occurring, and to diagnose and treat as early as possible neglect that is already present. Preventive measures, including strengthening maternal-infant bonding, nurturing nursery school and day care programs offering some of the love and concern that is absent in the home show promising results.

Treatment of children who are already victims of neglect is best managed by a team effort. Also it is strongly recommended that physicians and all parties involved should support and participate in professional and political efforts to solve social and economic factors that may underlie neglect, and that the articles of the Convention of the Rights of the Child concerning child health, child education, and child welfare should be informed, and communicated. These can be given through educarion to the individual family, community, non governmental organizations, professional organizations, government agencies. Such efforts should be included in the cur- riculum of training courses, schools, fac ulties of child health, child education, child welfare professionals, at all levels.

\section{References}

1. Johnson FJ, Coury DL. Child neglect: medical neglect. Child abuse. A Med References. Churchill Livingstone. 2nd Edition 321, 1992.

2. Kasim MS. Resolutions. Child abuse and the law. Proceeding of 2 d National Con ference of Child Abuse and Neglect, July
13-14, Kuala Lumpur, Malaysia 55, 1991.

3. Lynch M. Intrafamilial child abuse and neglect. Proceeding of the Pre 6th APF Seminar on Child Abuse and Neglect, 21 October 1992, Bali, Indonesia (in press).

4. Owen M, Coant O. Other forms of neglect. Child abuse. A medical reference. Churchild abuse. A medical reference. Chur349, 1992 .

5. Sudiyanto. Resolutions of the Pre 6th APF Seminar on Child Abuse and Neglect. Proceeding Pre 6th APF Seminar on Child Abuse and Neglect, 21 October 1992, Bali, Indonesia (in press). 